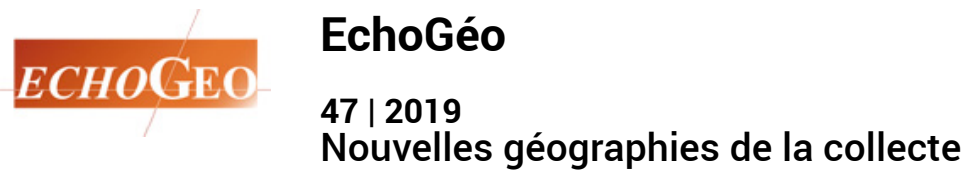

\title{
From Mushrooms to Pharmaceuticals: Cross- Disciplinary Perspectives on Logistical Regimes
}

E-mail interview with Mathieu Quet by Rémi de Bercegol and Lucie Dejouhanet, 11 March 2019

\section{Mathieu Quet, Rémi de Bercegol and Lucie Dejouhanet}

\section{CpenEdition} Journals

Electronic version

URL: https://journals.openedition.org/echogeo/20761

DOI: 10.4000/echogeo.20761

ISSN: 1963-1197

Publisher

Pôle de recherche pour l'organisation et la diffusion de l'information géographique (CNRS UMR 8586)

Electronic reference

Mathieu Quet, Rémi de Bercegol and Lucie Dejouhanet, "From Mushrooms to Pharmaceuticals: CrossDisciplinary Perspectives on Logistical Regimes ", EchoGéo [Online], 47 | 2019, Online since 30 January 2019, connection on 10 August 2021. URL: http://journals.openedition.org/echogeo/20761 ; DOI: https://doi.org/10.4000/echogeo.20761

This text was automatically generated on 10 August 2021.

EchoGéo est mis à disposition selon les termes de la licence Creative Commons Attribution - Pas d'Utilisation Commerciale - Pas de Modification 4.0 International (CC BY-NC-ND) 


\title{
From Mushrooms to Pharmaceuticals: Cross-Disciplinary Perspectives on Logistical Regimes
}

\author{
E-mail interview with Mathieu Quet by Rémi de Bercegol and Lucie
}

Dejouhanet, 11 March 2019

Mathieu Quet, Rémi de Bercegol and Lucie Dejouhanet

\section{REFERENCES}

Quet M., 2018. Impostures Pharmaceutiques. Médicaments illicites et luttes pour l'accès à la santé. Paris, La Découverte, 248 p.

Tsing A. L., 2015. The Mushroom at the End of the World: On the Possibility of Life in Capitalist Ruins. Princeton, Princeton University Press, 416 p.

- Rémi de Bercegol et Lucie Dejouhanet (RdB \& LD). Mathieu Quet, we would like to begin by introducing you to our readers as a resolutely field-oriented researcher. As a sociologist, you show a predilection for long-term, in-depth field work in remote and sometimes hard to access locations, using very similar methods to those used by ethnography. In your book's introduction, you mention how your approach requires you to "glean" information (Quet 2018,39 ): this brings us to the topic of this special issue, which focuses on collection. Can you explain more specifically what you mean by "gleaning"? How would you define your research practices? What is the role of field work in your research? What is the meaning of this empirical positioning?

- Mathieu Quet (MQ). The image of gleaning is very important to me. On the one hand, it implies that there is no research without going out there and searching for something. But this "something" we look for is not always specific: we identify places and people, and we set out in the hope of filling up our bag little by little. In addition, gleaners are always attentive to the new objects that appear in their field of vision. They are receptive to unexpected elements and bifurcations. You may be planning to collect information on a given object, and then find yourself following a path that you hadn't envisaged but looks fascinating. Research requires the same level of 
attention to the world. There is a tension between on the one hand individual and collective concerns, and on the other hand, unexpected events that keep driving us astray. This was how I started working on pharmaceutical issues in France, and was later drawn to India and Kenya, where I visited NGOs campaigning on access to medicine, but also interviewed stakeholders involved in the production and distribution of pharmaceuticals, as well as administrations in charge of regulating the circulation of drugs.

- RdB \& LD. You recently published a book entitled Impostures Pharmaceutiques, Médicaments illicites et luttes pour l'accès à la santé (2018) ("Pharmaceutical Imposture: Illicit Drugs and Struggles for Access to Health"). The book studies trade flows of drugs along with a controversy on the circulation of illicit pharmaceutical products. Can you give us a brief outline of this book for our readers who might not have read it yet?

- MQ. The book's main theme is the debates surrounding "fake" drugs. In short, we could say that the globalization of the production and consumption of pharmaceuticals went along with a growing number of issues in terms of quality, transport, preservation and legality, which are chiefly affecting developing countries. This issue is therefore a legitimate public health concern. But in parallel, the most powerful corporations (most of them European or North American) have been instrumentalizing this concern to impose their own vision of medicine, in particular in terms of intellectual property, thus excluding competitors from emerging countries. This is has been a cause for major confusion and conflict in the definition of what is a "fake" or a low-quality medicine. My study starts from these conflicts, following a sociology of public issues approach, but also investigates more broadly how drugs are produced, disseminated and controlled, based on interviews conducted mostly in India and Kenya, two countries that have been particularly affected by these issues. I think the originality of this book resides in part in the fact that it observes South-to-South flows. I come to the conclusion that in order to understand the issue of fake drugs, this issue needs to be considered in the global context of the securitarian dynamics that now characterize public health policies. I demonstrate that these dynamics are a way of governing the flows of medicine. I also suggest that the key factor at stake here is not so much the existence of "bad" drugs as the will to domesticate and control the circulation of commodities, which is manifested by the existence of such drugs.

- RdB \& LD. The starting point for your project is a controversy that was in part caused by a confusion between counterfeit and generic drugs, which has been threatening access to healthcare. This "controversy" stemming from constraints affecting access to drugs has in fact been the main point of focus of the reviews written on your book. This controversy is certainly a heuristic moment that helps us observe the world and decipher its tensions: similarly, Anna Tsing uses "capitalist ruins" as a driver for her narrative on the matsutake? Can you explain what the sociology of controversy means to you, and how you would define it?

- MQ. I work in the field of Science and Technology Studies. Controversies are of particular interest for researchers in this field for a number of reasons. First of all, scientific controversies often reveal quite clearly that science as an activity is never detached from social issues: in order to impose a given vision of the world, scientists draw upon their networks, thus deeply interweaving science and politics. Second, observing controversies or moments of instability allows us to analyze the making of scientific and social truth. These moments often reveal conflicting social rules and the implicit notions that underpin these rules. From this perspective, one can 
observe the world as a social and technical construct, as the object of perpetual shifts and reconfigurations.

- RdB \& LD. What is the role of space in your thinking? Without going as far as interpreting your work as a geography of controversy, there is something in your multi-scalar analysis of this phenomenon that brings geographic thinking to mind, in that it draws connections between seemingly very distinct spaces.

- MQ. In my research on drugs, I wanted to examine the trans-national deployment of a controversy that unfolded across multiple locations, and in particular India, Kenya and the European Union. This was an opportunity for me to test the scope of controversy analysis. From this point of view, my focus on space is that of a sociologist rather than that of a geographer. It is mostly based on a "multi-sited" approach (Marcus 1998), working from the following question: how can conflicts (on access to drugs) that emerge in such diverse and far-apart places as New Delhi, Nairobi and Brussels eventually converge into one trans-national controversy?

- RdB \& LD. Yes, and this is one of your common points with Anna Tsing's book, The Mushroom at the End of the World: On the Possibility of Life in Capitalist Ruins (2015). While these two books seem to address very different objects, considering them together sheds light on the notions of flows and changes of scale, and to quote Tsing, on the concept of "living-space entanglement". You even mention the astonishing odyssey of the matsutake mushrooms, that binds together "the fates of Oregon pickers with those of Japanese consumers" (164). Could you explain what you found of interest in Tsing's book and what captured your attention?

- MQ. Reading Anna Tsing's book had a huge impact on my own work, although the object of her study appears quite remote from my field. First of all, I am impressed with the freedom of this author's writing and with her conceptual creativity - with notions such as "contaminated diversity" or "scalability". More generally, through the object she chose to tackle (a mushroom picked by people who live in extreme poverty in American forests, sold to the Japanese for top dollar) and the way she tackles it, Tsing elucidates some of our society's essential traits: colonial and postcolonial history, the environmental crisis, the ravages of industrialization, the absurdity of capitalist value systems, etc. Her writing thus captures elements that we often attempt to understand in conjunction but that remain disjointed when approached solely through effects of scale.

- RdB \& LD. If you were to reinterpret your book in light of Anna Tsing's writing, to which extent does the circulation of pharmaceutical products (for example sofosbuvir, which you mention on p. 197) provide an illustration of "scalability", which Anna Tsing defines as "the ability of a project to change scales smoothly, without any change in project frames" (Tsing $2017,38)$ ? Ultimately, as trade flows have become global in a globalized capitalist society, why can't access to health also become more "scalable" globally?

- MQ. One important suggestion Tsing makes about scalability is that it requires some "work". Making projects "scalable" requires a full process of standardization involving sorting, eliminating, smoothing and domesticating activities. Tsing suggests that the very definition of "Progress" was based on this notion of scalability. She uses the notion as a means to reveal everything that, in contrast, appears to be "non-scalable" and resists scalability: the unruliness of "nature", the indocile bodies of slaves and workers, the phenomena that remain unexplained, etc. From this point of view, it would appear at a first glance that the drugs produced today by the biomedical industry are more or less the opposite of the matsutake: what could be more standardized than a drug? And yet, as you pointed out, if we consider Tsing's 
exploration of the non-scalable, it appears almost immediately that the protection of health (as a project) is not as scalable as it would appear. Medicine does not circulate so easily from one country to the next (due to intellectual property rights, but also to production standards). We could even go further by stating that the case of sofosbuvir reveals a conflict between two contrasting goals: on the one hand, the protection of health; on the other, the expansion of the pharmaceutical "sector" (or, to put it simply, of profit). It seems that for one of these two projects to be scalable (the expansion of the pharmaceutical sector), the other needs to be made nonscalable. For example, sofosbuvir is sold at an extremely high price in high and medium-income countries, and its owner has negotiated with Indian manufacturers permission to produce this drug on condition that they only sell it in certain countries (poor countries). The scalability of the pharmaceutical industry is ensured, and its global expansion has been guaranteed for the past century by production standards and copyright. However, this type of scalability clashes with another: that of the populations' health. I think this answers the last part of your question: the capitalist system today depends on scalability as a driver of commercial expansion. But that does not necessarily mean that all markets are served in a homogeneous manner - and in fact, the current system sees no issue with recurring shortages, in particular in developing countries.

- RdB \& LD. You analyze the pharmaceutical industry and its tentacular distribution channels through the prism of a logistical regime that organizes the maintenance and control of product flows, while invalidating the flows that elude its control. The logistical supervision of the supply chain and marketing networks plays a key part in controlling these fluxes. But as you note, "a logistical regime is not just a system that organizes circulations: it is also a political regime, that conveys a certain understanding of the distribution of power, of the construction of the public good, and of the political questions of justice and common good" (61).

- MQ. When I began studying the pharmaceutical industry, I was interested in how a public issue (the issue of "fake drugs") was defined. One of the key questions at stake here is: "What circulates?" - or rather, what is allowed to circulate by the states, firms and patients? As a consequence, to better understand this question, it appeared important to study these flows themselves, in order to clarify how they are governed. But in doing so, I also became aware of the close links between socio-political (how to fight "fake" drugs while ensuring access to medicine for as many people as possible) and logistical aspects (ensuring the production and distribution of drugs on an international scale). These links drove me to make the following hypothesis, inspired by geographical studies and in particular by Deborah Cowen's work (2014): the organization of the circulation of commercial goods involves the organization of social, political and economic relations in a given society. As a consequence, a logistical regime contributes to shaping society just as much as a political regime. For example, when corporations and States decide to authorize the circulation of certain drugs in certain countries and not in others, or when they introduce more stringent intellectual property laws, they are not just safeguarding financial returns for private parties: they are also imposing inherently political decisions on populations without consulting them. One important aspect of logistical regimes is the fact that they are built on the (transnational) circulation of consumer goods. For a long time, consumption was regarded as a relatively distinct activity from political life and citizenship - but today, many activities show that this is far from the case. 
- RdB \& LD. Nevertheless, deviations, branch outs and disconnections do occur in these flows, as illustrated by illicit drugs. What is their meaning?

- MQ. Working from the study of logistical regimes, my book draws mostly pessimistic conclusions. When considering pharmaceutical markets, the power of the corporations and of more developed countries is unchallenged. As a result, the populations have not yet reclaimed control over the logistical regimes - although the controversy on "fake" drugs I analyze shows that patients do sometimes strike back. On the other hand, I do not believe that individuals are totally powerless in front of the logistical regimes' dominant players. In my book, I also show that while a regime can impose specific trajectories and connections between flows, consumers are constantly diverting these trajectories and disconnecting these flows. In a way, we could say that in logistical regimes, agentivity consists first and foremost in this constant process of diverting and disjointing. We could even acknowledge that the citizens of these logistical regimes exert their power by connecting/disconnecting flows.

- RdB \& LD. Anna Tsing examines what happens in the sites where "salvage capitalism" extracts its supplies, which she refers to as "pericapitalist" spaces, and how other worlds are built on the ruins of what was formerly exploited. You chose as your book's epigraph a quote by Gilles Deleuze and Félix Guattari: capitalism has terrified all societies, provoking "an irrational fear of a flow that could elude their codes". If capitalism thrives from the absolute control of flows, by supporting some and destroying others, then how would you qualify the possibility of another world built on the ruins of capitalism? How could an antiOedipal reading bring us to reconsider Anna Tsing's book from a different perspective?

- MQ. One of the great strengths of Tsing's book is that it simultaneously shows capitalism's destructive power, its ability to renew itself and thrive from this very destruction, and the ability of life (both human and non-human) to persist in this system. The mushroom pickers whose lives Tsing writes about do not just make the best of a bad situation: they make life and society choices. Their lifestyles are not just reactions to the ravages of capitalism, although they are inseparable from them. From this perspective, the Deleuzian dimension of Tsing's work is quite clear (if only because of the rhizomatic nature of mycelium). If we read her book from an "antiOedipal" perspective, we can observe that the production of fluxes is indivisible from life: even in areas that have been ravaged by industrialization and exploitation, life persists in its indescribable and "senseless" way (flows crawl out in all directions, like the filaments of mycelium in the forests of Oregon). On the other hand, Deleuze and Guattari explain that capitalism thrives from its ability to constantly generate more flows and more connections between existing flows. Hence the markets' interest in the situations of chaos or devastation they have themselves contributed to producing. The ruins generate new flows, which spring from life itself, but capitalism is always alert and ready to capture these flows, to encourage them but also to redirect or domesticate them.

- RdB \& LD. All things considered, how do flows of matsutake mushrooms differ from flows of drugs?

- MQ. The domestication and assignation of flows is probably very different depending on whether one is dealing with drugs or mushrooms. In the case of drugs, a very heavy normative socio-technical apparatus is used to perform the sorting process, because the objective is to achieve the pharmaceutical project's scalability. This involves standards, copyright regulations, financial investments, etc. In the case 
of mushrooms, things are very different, as scalability is made more complex by the nature of the flows produced by the matsutake. Tsing shows that this creates volatility: in the products (and their quality, which may vary), in the markets and their foundational conventions, but also in the livelihoods that rely on this trade.

- RdB \& LD. You deliver a subtle analysis of the relation between what is legal and illegal, what is licit and illicit. But one term, which features repeatedly in this issue, is absent from your book: the notion of informality. Is this term not relevant to describe the processes at play in the circulation of drugs and the relations between the sector's stakeholders?

- MQ. Discussions on informality have definitely informed my research, and this term is used by many of those who study pharmaceutical markets from a socioanthropological perspective (see for example Carine Baxerre 2014). However, in spite of my work's proximity with these studies, I hardly ever use the word "informal" because I am not very comfortable with the binary it creates between what is regarded as "formal" and what is not. First of all, informal markets involve a range of formalizing practices (many informal players produce written documents contracts, accounts... -, the state is usually "aware" of their existence, etc.). Reversely, the actors of the formal market constantly resort to practices that are associated with informality (including, for example, bribing state officials). I believe that there is an element of formality in informality, and vice-versa. Besides, in the case I studied where people are trying to determine what is a "fake" or "poor quality" drug, or whether a copy is "legitimate" or "illegitimate", I think that a broad range of mechanisms can produce legality and illegality: the determinant factors affecting circulation and access can be best understood by attempting to describe these mechanisms with precision, rather than by resorting to the formal/informal binary that clouds the thinking more than one would think. However, I do not want to be too assertive on these notions: the discussion remains open to identify the words that can best help us grasp the characteristics of the markets we study.

- RdB \& LD. Another term rarely appears in your book - except where you describe your status as a young researcher at the beginning of your survey: precarity. And yet, this notion, which is one of the foundations of Anna Tsing's worldview ("Precarity is the condition of our time". Tsing 2015, 20), is present throughout your book: it could be applied to the patients with no access to official drug distribution channels, to resellers who become addicted to the drugs they peddle, to non-qualified distributors, etc. All these people who form part of the flows of illicit drugs are in a situation of vulnerability, of precarity, that forces them to divert the logistical regime, which is not adapted to their situation. The pharmaceutical industry's logistical regime produces precarity, by creating geographic, economic, social and political inequalities. Does this regime also thrive on these inequalities, although they appear to make it more vulnerable? Could a parallel be drawn between the characters you describe and the people Anna Tsing interviewed?

- MQ. The question of "precarity" is not articulated as such in my work, but I do fully endorse it. One obvious difference between my study and Tsing's is that the precarity she refers to is that of mushroom pickers, who are located upstream of the production-consumption chain, whereas the precarity I focus on in the case of drugs is that of consumers. In a way, the history of the consumption of matsutake mushrooms is that of the connection between the lives of vulnerable workers and luxury product consumers. When one focuses on pharmaceutical markets in developing countries, the relation is almost opposite: the drugs are produced by very large-scale businesses to be consumed by people who sometimes have very scarce resources and may go into lifelong debt due to a serious disease or accident. Precarity 
is therefore present in both cases, but I am more interested in the precarity of "citizens-consumers" who are subjected to the hazards of drug distribution, exposed to the power of corporations who can decide which country will be able to access a given drug and at what price, etc.

- RdB \& LD. Thank you, Mathieu Quet, for these stimulating answers. Before we close this interview, we wanted to ask you for your thoughts on the critique of the theology of Progress delivered by Anna Tsing: "Why would we expect economies to grow and sciences to advance?" (Tsing 2015, 21). How can this apply to the pharmaceutical industry as you describe it? The pharmaceutical industry works from the premise that innovation will always help improve treatments for patients, but is there still a place for "indetermination"? In this case, what could be its expression?

- MQ. Ah, this brings us to the very object of social science studies on science and technology! And I fully agree with Tsing's comment, which highlights the need to understand progress not just in a linear manner, as a process of positive growth. This theme has been addressed among others by the history and sociology of medicine, which showed for instance that the fight against epidemics cannot simply be understood through the sequence "outbreak - cure - eradication". In this respect, to understand the role of indetermination, I follow a number of authors like Didier Fassin (2018) who seek to deliver a more general definition of "forms of life" that articulates the molecular and socio-political levels - we live with viruses and within collectives of people! These forms of life are produced and destabilized by technical knowledge and markets, but reversely the latter also form part of the former and are "informed" by them. This is another reason why Tsing's book is so precious: beyond discourses on "growth", "knowledge" and the theology of Progress, the most effective way of making the world a more welcoming place perhaps requires us to understand life and its entanglements.

\section{BIBLIOGRAPHY}

Baxerres C., 2014. Du médicament informel au médicament libéralisé. Paris, Éditions des Archives contemporaines.

Cowen D., 2014. The Deadly Life of Logistics: Mapping Violence in Global Trade. Minnesota, University of Minnesota Press.

Fassin D., 2018. La Vie. Mode d'emploi critique. Paris, Seuil.

Marcus G. E. 1998. Ethnography in/of the World System: The Emergence of Multi-Sited Ethnography. In Ethnography Through Thick and Thin. Princeton, Princeton University Press, 79-104.

Quet M., 2018. Impostures Pharmaceutiques, Médicaments illicites et luttes pour l'accès à la santé. Paris, La Découverte.

Tsing A. L., 2015. The Mushroom at the End of the World: On the Possibility of Life in Capitalist Ruins. Princeton, Princeton University Press. 


\section{NOTES}

1. The matsutake is a mushroom that grows under tall pine trees in Oregon forests that have been damaged by the logging industry. It is one of the most expensive and sought after foods in the world, in particular in Japan where it is now imported.

\section{AUTHORS}

\section{MATHIEU QUET}

Mathieu Quet, mathieu.quet@ird.fr, is a researcher at IRD (French National Research Institute on Sustainable Development) and a member of the CEPED Research Unit (populations and development). In addition to Impostures pharmaceutiques, his recent publications include: - Dumoulin Kervran D., Kleiche-Dray M., Quet M., 2019. Going South. How STS could think science in and with the south? Tapuya, Latin American Science, technology and society [online], 1 (1), 280-305. DOI: https://doi.org/10.1080/25729861.2018.1550186

- Al Dahdah M., Kumar A., Quet M., 2018. Empty stocks and loose paper. Governing access to medicines through informality in Northern India. International Sociology, 33 (6), 778-795.

- Quet M., 2018. Pharmaceutical capitalism and its logistics: access to hepatitis C treatment. Theory Culture and Society, 35(2), 67-89.

\section{RÉMI DE BERCEGOL}

Rémi de Bercegol, remi.debercegol@cnrs.fr, is a CNRS Researcher (Centre National de la Recherche Scientifique) and a member of Research Unit PRODIG (Development, Global Change and Territorial Dynamics). In Delhi, he co-organized the exhibition The City of Waste, from which the photographs have been extracted. His recent publications include:

- de Bercegol R., 2019 [1st ed. 2010]. Small Towns and Decentralisation in India. Rawat Publications [1st ed. Springer].

- de Bercegol R., Gowda S., 2018. Waste and Energy Nexus: Rethinking the modernisation of waste services in Delhi. Urban Studies, Special Issue on 'Urban Nexus', June 2018.

- de Bercegol R, 2018. Les enjeux de la valorisation des déchets à Delhi. In Jaglin S, Debout L., Salenson I., (eds.), Du rebut à la ressource, Valorisation des déchets dans les villes du sud. Paris, AFD, 31-49.

\section{LUCIE DEJOUHANET}

Lucie Dejouhanet, lucie.dejouhanet@orange.fr, is an Associated Professor of Geography at Université des Antilles, AIHP-GEODE EA 929. Her recent publications include:

- Dejouhanet L., 2014. Supply of Medicinal Raw Materials. The Achilles Heel of Today's Manufacturing Sector for Ayurvedic Drugs in Kerala. Asian Medicine, 7(3), 206-235.

- Dejouhanet L., 2014. Secteur informel et réseaux de commercialisation des plantes médicinales au Kérala (Inde). Économie rurale, 343, 53-70.

- Dejouhanet L., 2017. Tourism in the mountains of Central Kerala (South India): at the Crossroads of attitudes toward forest populations. Journal of Alpine Research, 105(3). 